\title{
INSTRUMENTALIZAÇÃO DE VULNERÁVEIS PARA PESQUISAS
}

INSTRUMENTALIZATION OF VULNERABLES FOR RESEARCH

\author{
Maria Auxiliadora Minabim ${ }^{1}$ \\ UFBA \\ Natalia Petersen ${ }^{2}$ \\ UFBA
}

\begin{abstract}
Resumo
O trabalho tem como objetivo desvelar a prática de pesquisas com alto percentual de risco, envolvendo pessoas de autonomia reduzida, em oposição ao princípio da proteção absoluta da vida. O trabalho foi realizado a partir de revisão na literatura sobre as investigações em humanos, recorrendo-se, tanto a autores da área do Direito, quanto aos da Bioética e da Filosofia, analisando os dados coligidos numa perspectiva crítica. Resultados: os princípios e as normas não impedem a manipulação dos vulneráveis para experiências e pesquisas com fins ditos científicos. Há uma franca contradição entre algumas investigações e a proteção do vulnerável na medida em se que busca o baixo custo do projeto e o silêncio dos "voluntários".
\end{abstract}

Palavras-chave

Proteção jurídica da vida. Pesquisas clínicas. Cobaias humanas. Normas supranacionais. Autonomia. Vulnerabilidade.

\section{Abstract}

The work aims to reveal the practice of research with a high percentage of risk, involving people with reduced autonomy, in opposition to the principle of absolute protection of life. Methodology: the work was carried out from a review of the literature on investigations of humans, using both authors in the area of Law, as well as those from Bioethics and Philosophy, analyzing the data collected in a critical perspective. Results: the principles and norms do not prevent the manipulation of the vulnerable for experiments and research with scientific purposes. Conclusion: there is a clear contradiction between some investigations and the protection of the vulnerable while seeking the low cost of the project and the silence of the "volunteers".

Keywords

${ }^{1}$ Professora Titular de Direito Penal na UFBA. Doutora em Direito das Relações Sociais UFPr.

${ }^{2}$ Mestre e Doutora em Direito pela UFBA. Advogada em Direito Médico. 
Legal protection of life. Clinical research. Human guinea pig. Supranational norms autonomy. Vulnerability

\section{INTRODUÇÃO}

As relações sociais são pautadas no plano normativo pelo ideal de respeito e reconhecimento de cada qual como um par, um igual. A vida do outro é considerada intangível e dotada dos atributos da dignidade e da autonomia, predicados que pretendem honrar a espécie. Ocorre, todavia, que as pessoas são expostas a situações que podem desencadear debilidades em sua autonomia, seja por problemas cognitivos, disfunções ou alterações orgânicas (dentre as quais se inclui o envelhecimento), exclusão social ou econômica. O foco do estudo é a utilização de idosos, presos e econômica e socialmente carentes como cobaias em pesquisas. São circunstâncias, diante das quais cabe, mais intensamente, o reconhecimento do outro como sujeito de direitos, mas, sua fragilidade pode ser instrumentalizada em favor de interesses diversos. É nítida a contradição estabelecida entre a prática e o discurso que, por abuso de direito, pretende contornar as regras jurídicas estabelecidas para fazer pesquisas sobre parcelas vulneráveis da população. No plano jurídico, todavia, a dignidade humana, fundamento de todos os direitos, e a vida, bem fundamental sem o qual não há que se falar em dignidade, são bens que continuam sendo considerados invioláveis. O trabalho tem como objetivo desvelar situações que, em plena era de direitos, são toleradas e repetidas mesmo ao arrepio de construções garantidoras da intangibilidade da vida humana.

\section{O DIREITO ABSOLUTO À VIDA}

Aprende-se que o direito à vida é um direito absoluto. A afirmação compreende o direito do titular, à própria vida, o dever do estado de protegê-la e o dever de abstenção dirigido a todos, inclusive ao Estado, de não praticar atos que atinjam a vida. Assim, ela seria indisponível mesmo 
para seu portador que, ademais, pode demandar a todos o dever de renúncia a atos que atentem contra esse bem.

Ocorre que, mesmo nessa perspectiva normativa há exceções abertas ao seu ataque pelo próprio direito. Num jogo de palavras, diz-se que o direito à vida é absoluto enquanto direito, mas isto não significa respeito absoluto a este valor na medida em que o próprio sistema jurídico abre espaços para certas formas de ataque a esse bem $^{3}$. Exemplo concreto é o oferecido pela própria Constituição Federal no artigo $5^{\circ}$, inciso XLVII, que admite aplicação de pena de morte em casos de guerra declarada. Da mesma forma ocorre com a relativização proporcionada pelo instituto da legítima defesa, e pelas demais excludentes de ilicitude. O suicídio é outra forma de destruição da vida permitida pela ordem jurídica cuja tolerância esteve mais ligada a razões de política criminal (desnecessidade da pena) e menos a questionamentos filosóficos sobre a disponibilidade sobre a própria vida. Pode-se concluir, portanto, que nenhum direito é intangível porque pode ser relativizado, por exceção, em situações autorizadas pela ordem jurídica. Dessa forma, o princípio do respeito absoluto à vida pode ser afastado para que outro princípio seja exercido em sua plenitude, ou seja, adota-se aquele cuja aplicação proporcione um maior ganho conforme as expectativas abrigadas pelo sistema jurídico e os valores éticos. Essa interpretação poderá ser guiada pelo meta critério da proporcionalidade e seus princípios orientadores: adequação, necessidade (restrição ao excesso, ou seja, a convocação do princípio aplicado não deve importar em restrição muito grande daquele que foi preterido) e proporcionalidade em sentido estrito que envolve uma análise da relação custo benefício do princípio escolhido em relação ao afastado.

Ocorre que esta última reflexão pode ser fundamentada, e o é em grande parte por razões utilitaristas. Em muitas situações a violação da vida - e da saúde que permite sua fruição enquanto direito - se dá de forma silenciosa,

${ }^{3}$ MESTIERI, João. Curso de direito Criminal. São Paulo: Alba, 1979, p.30. 
insidiosa, através da instrumentalização dos mais vulneráveis com o fim de obtenção de benefícios para a população socioeconomicamente dominante. Ocorre, na verdade, como salienta Roselló ${ }^{4}$, que a vulnerabilidade faz outro tipo de apelo. Ela solicita uma relação de não indiferença, de acolhida e de solicitude.

Curiosamente, todas as violações à vida, pela submissão de vulneráveis à condição de coisa, seja pelo descarte, seja pelo uso que deles se faz, convivem com discursos asseguradores de direitos, respeito às diferenças e solidariedade. São cada vez mais frequentes as declarações e pactos internacionais que pretendem garantir consideração a cada pessoa que integra a comunidade humana. Pode-se lembrar desde a Declaração Universal dos Direitos Humanos (DUDH), o Pacto Universal dos Direitos Econômicos, Sociais e Culturais (PIDESC), Pacto Internacional dos Direitos Civis e Políticos (PIDCP) Regras de Beijing, Declaração dos Direitos Criança e muito outros que a missão é promover a fraternidade e o igual uso de recursos sustentáveis para todos. É possível que a quantidade de normas estabelecidas corresponda à mesma falta de compromisso com seu cumprimento, daí que se desdobrem em quantidade e em especificidade. O fato é que tudo indica que, a não ser no âmbito do direito formal, não existam direitos absolutos, uma vez que, mesmo o menosprezo à dignidade - atributo que nos faz humanos - são realizados por negligência do Estado, desinteresse ou preconceito da sociedade.

\section{VIOLAÇÃO E PROTEÇÃO DA VULNERABILIDADE}

Um espaço recorrente de abuso dos mais frágeis é o da pesquisa na área de saúde, na medida em que apenas algumas poucas pessoas realmente se voluntariam para submeter-se a riscos desconhecidos.

${ }^{4}$ ROSELLÓ Francesce Torralba. Ideias de dignidade. Uma exploracion filosocfica. Em:Martinez, Julio Perrotin Catherine, TORRABA, Francese. Repensar la dingidad humana. San Salvador: Milenio, 2005, p. 15-92. 
Durante muito séculos, o médico teve um controle quase absoluto na relação com seu paciente, fosse pelo poder que detinha, fosse pela confiança nele depositada. Após a Segunda Guerra Mundial, todavia, a relação médico-paciente, até então com forte cunho paternalista ${ }^{5}$, restou sensivelmente abalada em sua estrutura, quando se tornaram públicas as pesquisas desumanas desenvolvidas por médicos nazistas com prisioneiros em campos de concentração. Byrd ${ }^{6}$ lembra as experiências de congelamento e mutilação de membros de prisioneiros para que fossem descobertos tratamentos para queimaduras resultante de exposição extrema ao frio. Os presos tinham os braços expostos e molhados regularmente com água até congelarem. Os médicos procediam da mesma forma com as pernas até que, após cada amputação, restasse apenas a cabeça e o torso. A vítima era então usada para experimentos com pestes e patógenos.

No campo de concentração Nazista de Auschiwtiz, Miklos Nyisli, médico judeu recrutado compulsoriamente, destaca que diariamente corpos de prisioneiros eram enviados para que fossem abertos, analisados e retalhados. Eram ciganos, alemães portadores de necessidades especiais, prisioneiros soviéticos e judeus para execução de "estudos". Os corpos eram posteriormente enviados para que fossem abertos e necropsiados, visando o melhor conhecimento dos processos patológicos que afetam a espécie. Crianças eram também vítimas desses procedimentos, sendo muitas vezes

5 O paternalismo parte do princípio de que um dos sujeitos possui maior capacidade e conhecimento, atuando em relação ao outro como se fosse um pai em relação aos seus filhos, sempre no sentido de executar as melhores ações, dirigidas à produção de seu bem estar, sem que necessariamente este sujeito precise participar da tomada de decisão ou concordar.

${ }^{5}$ GRECO, Dirceu. WELSH, James. Direitos humanos, ética e prática médica. Revista Bioética. Vol. 24(3), 2016 - p. 443-451. p, 446. Disponível em: https://www.scielo.br/pdf/bioet/v24n3/1983-8042-bioet-24-03-0443.pdf

${ }^{6}$ DEAN, Gregory. General Ishii Shiro: His Legacy is that of a Genius and Madman. Electronic Theses and Dissertations. Paper 1010. Disponível em: https://dc.etsu.edu/etd/1010. 2005. 
deliberadamente mortas para que seus corpos fossem submetidos a investigações ${ }^{7}$.

$\mathrm{Na}$ Unidade 731 do campo de concentração japonês, experiências praticadas, em sua maioria com prisioneiros chineses, incluíam infecção deliberada com bactérias, exposição a frio, radiação e pressões intensas, bem como vivissecção em pessoas vivas e conscientes, ultrapassando supreendentemente o limite de outras ações cruéis já praticadas contra a raça humana ${ }^{8}$.

Constatou-se, após estes episódios, que assim como os demais seres humanos, os médicos eram também capazes de condutas impiedosas, violando o juramento de Hipócrates, para satisfazer o interesse de alguns em detrimento da vida de outros.

Diante de tal realidade, em 1946, elaborou-se o Código de Nuremberg, estipulando princípios éticos básicos para a experimentação com seres humanos, dentre os quais podem ser enumerados o da voluntariedade da participação nos estudos, o da autodesignação autônoma do paciente, o da produção de benefícios ao experimentando e o da análise de risco prévia ao estudo com a finalidade de evitar a produção de consequências danosas, com sofrimentos desnecessários?.

Ocorre, todavia, que, de acordo com os estudos de Débora Diniz e Dirce Guilhem $^{10}$, o referido instrumento normativo não foi suficiente para que os abusos de experimentos cessassem, fato este denunciado por Henry Beecher, na década de sessenta, segundo o qual havia parte significativa de pesquisas realizadas com humanos, nos Estados Unidos da América, que

${ }^{8}$ GRECO, Dirceu. WELSH, James. Direitos humanos, ética e prática médica. Revista Bioética. Vol. 24(3), 2016 - p. 443-451. p, 446. Disponível em: https://www.scielo.br/pdf/bioet/v24n3/1983-8042-bioet-24-03-0443.pdf

${ }_{9}^{9}$ Disponível em https://www.ufrgs.br/bioetica/nuremcod.htm. Acesso em maio/2020 ${ }^{10}$ DINIZ, Débora. GUILHEM Dirceu. O que é bioética. São Paulo: Brasiliense, 2007. Passim 
não respeitavam critérios mínimos de ética, tampouco os princípios elencados pelo diploma normativo retro citado.

Tomou-se conhecimento de estudos levados a cabo naquele país, a exemplo daquele de Tuskegee ${ }^{11}$, que envolveram a observação do desenvolvimento de sífilis em pessoas negras e pobres sem lhes dispensar qualquer tratamento; os realizados em Willowbrook, uma escola para crianças portadoras de retardo mental, que consistiam em inoculação de vírus da hepatite $^{12}$ e, ainda, a exposição de crianças com retardo mental, internadas na Escola Fernald State ${ }^{13}$, a radiação para acompanhar a absorção de cálcio e ferro pelo organismo humano, causaram perplexidade. Tais fatos denunciaram o abuso nas experiências com vulneráveis.

Como bem destaca Marcio Hernández, o Relatório Belmont foi impulsionado sobretudo pela descoberta da referida investigação sobre a sífilis que foi levada a cabo pelo sistema público de saúde norte americano e desencadeou centenas de mortes. O projeto durou cerca de quatro décadas (dos anos trinta aos anos setenta), durante o qual diversos indivíduos foram privados de tratamentos já existentes para a cura da infecção, com a finalidade de propiciar o estudo acerca da evolução da enfermidade. Além disso, ao que consta nos registros históricos, nenhum dos sujeitos tinha conhecimento que fazia parte de um estudo, sabendo apenas que era

${ }^{11}$ ROTHMAN, David J. Were Tuskegee and Willoubrook Studies in Nature? The Hasting Centrer Report vol. 12, $\mathrm{n}^{\circ}$ 2, abr. 1982, pp.5-7. p.5. Disponível em: http//jstor.org/stable/3561798. Acesso em: 21 maio 2019

12 O fim da experiência era o de comprovar se os anticorpos extraídos de uma pessoa infectada por hepatite injetados em uma pessoa não infectada, tornariam essa pessoa imune à doença ou sujeita a formas mais brandas caso as contraíssem. Disponível em: https: ética em conflito.wordpress.com/pesquisas-com- hepatite-na-escola-estadual-de-willowbrook. Acesso em 21 maio 2019.

${ }_{13}$ Disponível em: https//ahrp.org.1944-1956-radioative-nutrictions experiments. Acesso em 21 maio 2019. 


\section{DeLiCTAE, Vol. 6, No10, Jan...-Jun. $2021 \mid \mathbf{5 5}$}

portador de uma enfermidade, sendo privados do tratamento através da penicilina, acessível desde $1940^{14}$.

Não fosse suficiente, em meados dos anos quarenta, o governo americano em conjunto com o da Guatemala, conduziu experimentos sobre doenças sexualmente transmissíveis sem obedecer a qualquer pauta ética. Além da produção de infecção de soldados, prisioneiros, prostitutas e pessoas com transtornos mentais por inoculação direta, os experimentos envolviam a contratação de profissionais do sexo contaminadas com sífilis, gonorreia ou cancroide, para que mantivessem relações sexuais com prisioneiros, com o intuito de analisar os efeitos da penicilina no tratamento destas enfermidades. Em nenhuma das situações o consentimento informado fora tomado ${ }^{15}$.

Acerca de situações dessa natureza, David Rothman afirma que o julgamento dos médicos nazistas não produziu o efeito que deveria ter produzido, inibindo condutas criminosas e antiéticas. Tal teria ocorrido porque as pessoas, de modo geral, não supunham que médicos comuns pudessem praticar atos com as características daqueles realizados pelos nazistas. Em suas palavras, “[...] eles acreditavam que os experimentos bizarros e cruéis não haviam sido produzidos por cientistas e médicos, mas por oficiais sádicos"16.

Já em 1964, a Declaração de Helsinque, produzida a partir de considerável influência do Código de Nuremberg, recomendou a criação de comissões independentes para avaliação dos estudos com humanos, seguida em 1974, pela Nacional Research Act, norma criadora da National Commission for the Protection of Human Subjects of Biomedical and Behavioral Research. Essa Comissão

14 GRECO, Dirceu. WELSH, James. Direitos humanos, ética e prática médica. Revista Bioética. Vol. 24(3), 2016 - p. 443-451. p, 448. Disponível em: https://www.scielo.br/pdf/bioet/v24n3/1983-8042-bioet-24-03-0443.pdf

16 Rothman, David J. Strangers at the Bedside: a History of how Law and Bioethics Transformed Medical Decision Making. USA. Basic Books, 1991. IN Op. Cit, 17. 
tinha a incumbência de produzir um documento com diretrizes para a garantia da implementação de pesquisas sob o crivo de princípios éticos, resultando no conhecido Relatório de Belmont ${ }^{17}$, publicado em 1979. Esse relatório trouxe, em seu corpo, princípios orientadores da ética em pesquisa, quais sejam: o respeito pelas pessoas (autonomia), a beneficência e a justiça, os quais possuem notória inspiração nos dispositivos apresentados em Nuremberg. Tais documentos representavam a indignação dos cidadãos diante dos fatos recém descobertos

Não obstante essa e outras normatizações sobre a proteção ao voluntário em pesquisa, em 2003, teve-se conhecimento de experiência mais próxima sobre malária, realizada pelo Instituto de Estudos e Pesquisas do Amapá (IEPA) e pela Universidade da Flórida. Nesta investigação, a pessoa deveria deixar-se picar por mosquitos nos braços ou pernas em troca de remuneração de $\mathrm{R} \$ 12,00$ por noite. A pesquisa foi suspensa pelo Ministério Público porque atentava contra Resolução 196/96 do Conselho Nacional de Saúde e contra o Código de Nuremberg já referido. Ademais, foi considerado que o consentimento fora obtido sem esclarecimentos suficientes, sobretudo apreciando a condição de ser a população escolhida semianalfabeta ${ }^{18}$.

\section{AUTONOMIA DOS PARTICIPANTES}

${ }^{17}$ FERRER, Jorge José. ALVAREZ, Juan Carlos. Para fundamentar bioética: teorias e paradigmas teóricos na bioética contemporânea. p,73.

${ }^{18}$ Conforme BUARQUE, C. Relatório sobre o caso das cobaias humanas no Amapá. Disponivel em: $<$ http://www.mp.ap.gov.br/noticia/leiamais.php?codnoticia=298>. Acesso em: 13 jun. 2020.

FAIVRE, Anne-Sophie Le Cader,. Le coronavirus, les tests de vaccins et l'Afrique: où en est-on? Disponível em: https://factuel.afp.com/le-coronavirus-les-tests-de-vaccins-etlafrique-ou-en-est 
A autonomia, a partir da década de oitenta, passou a assumir um espaço importante na Bioética, compreendida como princípio capaz de pôr limites às intervenções abusivas no ser humano. É considerada como pré-requisito para o exercício da moralidade e, só através do respeito a essa condição, será possível legitimar uma intervenção sobre terceiros.

Para Kant, o maior artífice do conceito, autonomia é o uso da vontade para cumprir a lei moral capaz de ser conhecida através da razão. Tal ocorre em razão do livre arbítrio, ou seja, pela capacidade de, tendo conhecido o bem, poder realizá-lo por decisão própria e não de terceiros (auto nomos). Segundo o filósofo ${ }^{19}$, "autonomia é liberdade da vontade, a vontade é, em todas as ações, uma lei para si mesma".

No campo da relação médico paciente, é também a deferência a esse atributo que pode viabilizar a simetria desejada nessa relação.

Não há um processo seguro que permita determinar infalivelmente se uma pessoa dispõe ou não de autonomia. Como diz Becky White ${ }^{20}$, a capacidade para consentir requer uma série de outras competências, que podem ser agrupadas em quatro categorias: capacidade cognitiva e afetiva, capacidade de absorver a informação que lhe é prestada, capacidade para fazer escolhas e capacidade para reconstruir o próprio processo decisório. Para aceitar uma manifestação de vontade como efetiva concretização de autonomia, o pesquisador ou o médico teriam que conferir todos esses atributos, o que é uma tarefa muito difícil, sem um padrão uniforme.

A dificuldade em estabelecer um limite rígido entre pessoas autônomas e pessoas não autônomas, ou melhor entre decisões autônomas e não autônomas, em face das múltiplas camadas de qualidades que compõem seu sentido, cria uma zona cinzenta na qual, a não ser arbitrariamente, decidese em um ou outro sentido. Imagine-se um atleta olímpico que fratura o braço e que percebe, pela extensão da lesão que não poderá mais competir,

${ }^{19}$ KANT, Emanuel. Fundamentação da metafísica dos costumes. Lisboa: Edições 70, 2007, p. 94. ${ }^{20}$ WHITE, Becky Cox. Competence to consent. Washington: Georgetown University Press, 1994. Pp. 44-53; 
negando seu consentimento para cirurgia. Ou, uma mulher claustrofóbica que, se vendo presa em quarto pequeno, pede ajuda para morrer. Trata-se, em ambos os casos, de pessoas pressionadas por circunstâncias que lhe afetam a capacidade de decisão.

De outro lado, a capacidade afetiva íntegra pode levar um portador de Alzheimer a desejar voltar para junto de seu parente, mesmo sendo este incapaz de lhe dispensar os cuidados necessários, mas em cuja companhia prefere viver.

O Relatório Belmont já se referia a pessoas saudáveis, em tese autônomas, cujas decisões padecem dessa qualidade, restringindo sua participação em experimentos. Há menção expressa no documento aos prisioneiros que, por estarem em situação de isolamento e cerceamento de liberdade, podem ser conduzidos à aceitação de doação ou a investigações científicas. Há notícias, por exemplo que, na China, grande parte dos órgãos destinados a transplantes provêm de prisioneiros executados. O Tribunal Popular Supremo em face da divulgação do fato, afirmou que as doações são voluntárias. No entanto, o Human Rights para a China afirmou que os métodos de obtenção dos órgãos não são claros e que as autoridades da prisão obtêm diretamente do condenado o consentimento, obrigando os presos a assinarem o documento de doação ${ }^{21}$.

Note-se que tal dispositivo no Relatório, acerca da participação de sujeitos vulneráveis em pesquisas, decorre do fato da reiterada submissão de pessoas nessa situação para experimentos, porque são mais facilmente manipuladas, e por integrarem grupos que dificilmente identificarão os riscos ou se insurgirão contra eles.

${ }^{21}$ COHEN, Claudio, BUCCI Daniela A doação compulsória de órgãos e os prisioneiros condenados à morte: uma análise sob o ponto de vista da bioética. Revista de. Bioética. Brasília: Conselho federal de Medicina, 2011; 19(2): 383 - 96.O Partido e a profissão: abuso de transplante de órgãos na China. A profissão global de transplante tem, lamentavelmente, se tornado parte do problema. Disponível em: https://www.epochtimes.com.br/partidoprofissao-abuso-transplante-orgaos-china/ Aceso em: 5 jul. 2020. 


\subsection{AUTÔNOMOS VULNERAVEIS}

Beauchamp e Childress $^{22}$, dois filósofos norte-americanos, ao desenvolverem seus estudos sobre ética biomédica conduzem a aplicação dos princípios para além do campo da pesquisa sobre humanos, tornando conhecido o chamado sistema principialista para orientar ações nessas áreas. Propondo uma equivalência relativa entre as virtudes e os princípios, operam a transformação destes em quatro, distinguindo beneficência e nãomaleficência que se referem respectivamente à ideia: de realizar ações que beneficiem os outros e abster-se de ações que causem lesões às pessoas. No que diz respeito aos sujeitos da pesquisa, referem-se à obrigação, por exemplo, de não causar danos, para tanto utilizando procedimentos de baixo risco - não maleficência - e de, por outro lado, àquela de prestar auxílio a quem foi lesado no decorrer da pesquisa - beneficência. A não maleficência preponderaria sobre a beneficência, embora os autores alertem que não é possível estabelecer por antecedência a prioridade de um, sobre outro princípio.

O quarto princípio, o da justiça, pode ser, abreviadamente, compreendido como um tratamento justo para todas as pessoas na área de saúde. Como esse trabalho não comporta uma teoria da justiça, pode-se apenas lembrar um dos possíveis sentidos que lhe foi atribuído, o de equidade, cujo uso, mesmo se pensando em recursos escassos, permitiria cada pessoa partilhar das conquistas científicas. Até o ano 2000, apenas o Relatório americano se referia a este princípio, mas então foi adicionado à Declaração de Helsinque

22 BEAUCHAMP, T.L. \& CHILDRESS, J.F. Princípios de Ética Biomédica. (4 ed.) São Paulo: Edições Loyola, 2002. p. 210-211.7ALBUQUERQUE, Aline Para uma ética em pesquisa fundada nos Direitos Humanos. Rev. Bioética, Brasília: CFM. 2013; pp. 412-22, p. 416. 
com o sentido de justa distribuição dos benefícios, entendendo-os às pessoas que participaram das pesquisas.

Deve-se ressaltar que o fato de o princípio da justiça ter sido inserido em Normas Internacionais não trouxe maior segurança para os vulneráveis, uma vez que continuaram frequentes os ensaios e testes com populações de regiões mais pobres, na medida em que estes têm padrões regulatórios mais frágeis e custos indenizatórios mais baratos

\subsection{VULNERABILIDADE ACRESCIDA}

A palavra vulnerabilidade é derivada da expressão "vulnerabilis" que, em latim, remete à aquele que causa lesão, bem como à palavra "vulnerable" que indica o indivíduo que ocupa o polo passivo da lesão, de modo que o vulnerável seria aquele que pode ser ferido, lesionado, machucado. Todavia, em que pese sejamos todos vulneráveis, frente à condição universal que atinge a todos os seres humanos, nem todos são atingidos igualitariamente com tais susceptibilidades, tampouco reagem de maneira igualitária a tais circunstâncias ${ }^{23}$.

Miguel Kotow $^{24}$ assevera que a vulnerabilidade constitui atributo antropológico decorrente da condição biológica e existencial do ser humano, que se encontra em constante risco de danos. Fala também em pessoas vulneradas, que seriam as mentalmente, biologicamente ou socialmente fora do padrão mínimo de normalidade, pois se tornam especialmente susceptíveis e predispostas a danos adicionais.

23 LINS, Emmanuela Vilar. As dimensões da vulnerabilidade bumana: como condição, como característica e como princípio bioético-jurídico. Salvador: Universidade Federal da Bahia, 2007, p. 12.

${ }^{24}$ KOTOW, Miguel. Participación informada em clinica e investigación biomédica: las multiples facetas de la decisión e el consentimento informados. Red Latinoamericana y del Caribe de Bioética: Universidad Nacional de Colombia, 2007, p.43. 
A ideia de vulnerabilidade, assim como a de autonomia, está associada ao próprio ser humano como condição que lhe é inerente e que pode alterar impositivamente sua tomada de decisão, obstando o exercício de sua plena liberdade. Reconhece-se, ademais que, além da vulnerabilidade como condição, há aquelas que são acrescidas. As vulnerabilidades acrescidas, precisam ser ponderadas quando se indaga sobre a autonomia, conforme já reconhecia o Relatório Belmont, que admitiu a necessidade de proteção dos sujeitos que apresentam a autonomia de forma diminuída.

Tais vulnerabilizações possuem diversas faces, podendo se apresentar como susceptibilidades físicas, econômicas, educacionais, psicológicas, afetivas, políticas, religiosas, geográficas, históricas, institucionais, dentre outras. Além disso, não se pode ignorar a possibilidade de ocorrência de mais de um tipo de circunstância vulnerabilizante ao mesmo tempo em um único indivíduo, interferindo decisivamente no rumo de sua vontade. Com esse conhecimento há que se refletir sobre a inteira autonomia do "voluntário" em pesquisas.

Emmanuela Lins ${ }^{25}$ trata sobre alguns fatores capazes de afetar a autonomia individual, tais como, debilidade cognitiva, presença de autoridade ou estado de submissão, alterações orgânicas e exclusão social. Além destas, exatamente pelo déficit de que padecem, muitos ainda são alvo de vulnerabilidades afetivas e psicológicas devido ao abandono de suas famílias, parentes e falecimento de seus amigos, deixando-os mais propensos à decisões desesperadas e desapegadas. Assim, não é temeridade afirmar que são compelidos, quando consultados a participar de pesquisas pelo impulso de se sentirem úteis e valiosos à sociedade que os abandonou e os fizeram parecer apenas dispendiosos.

As vulnerabilidades geográficas destacam-se pelas diversas fragilidades que apresentam. A primeira delas está relacionada ao fato de que países

25 VILAR, Emmanuela. As dimensões da vulnerabilidade humana: como condição, como característica e como princípio bioético-jurídico ... op. cit., p 110-121. 
subdesenvolvidos possuem sistemas de saúde menos eficientes e quadros institucionais assolados por eventos recorrentes de corrupção, que reduzem a capacidade de atendimento a cada região devido ao mal emprego do dinheiro público e aos diversos desvios sofridos ao longo do percurso. Tais circunstâncias geralmente são agravadas pela vulnerabilidade educacional, econômica e política da população desses lugares. O segundo fator é que pessoas nascidas em tais regiões comumente são vistas como subumanas, menos dignas e menos valiosas como resultado da herança escravocrata dos brancos europeus que não foi extinta completamente. Assim, o cuidado na execução de experimentos deve ser redobrado e a pesquisa constantemente fiscalizada, haja vista que a experiência já demonstrou o recorrente desrespeito a princípios humanitários em estudos clínicos realizados em continentes como África, Ásia e América Latina. Os testes de HIV na África tornaram claro que os sujeitos submetidos à pesquisa arcaram com os ônus dos estudos, pouco usufruindo dos bônus ${ }^{26}$. A escolha de regiões do continente repita-se, deve-se à situação de indigência econômica de muitos países africanos que coloca seus cidadãos em uma tal situação de pobreza econômica e cultural que os impede de estabelecer relações simétricas com estrangeiros.

Idosos, muitas vezes, são vítimas de vulnerabilidades físicas, econômicas, afetivas, psicológicas e institucionais, afinal, possuem costumeiramente um corpo que expressa a evolução de tempo e das vivências, que em muitas situações carregam consigo elementos de comorbidade. Há, em muitos, um declínio intelectual, da capacidade de fala, de memória, os quais, dispensados de exercício na atividade relacional, entram em franco declínio. Não é sem propósito que é nesses grupos, nos quais a capacidade de falar e ser ouvido é diminuída, que são feitas pesquisas com risco para a vida e para a saúde dos "voluntários". Ainda que haja consentimento, muitas vezes este

${ }^{26}$ (Roy Mugerwa et aI., First Trial of the HIV-J Vaccine in AJi'iea: Ugandan Experience,324 BRITISH MED. J. 226, 228 (2003); 
padece dos requisitos necessários para expressar a livre vontade da pessoa, o que pode consistir em Crime de Constrangimento Ilegal ou de Lesões corporais, conforme o caso. Não basta que se apregoe a autonomia para consentir e que houve consentimento para pesquisa, é preciso a atenção diferenciada à vulnerabilidade de cada um, contando com a assessoria de comitê ético.

\section{CONSIDERAÇÕES FINAIS}

Com o fim de promover uma convivência tão harmônica quanto possível, o direito dispõe através de seus princípios e regras sobre o comportamento a ser desenvolvido pelos seus membros. No dizer do finalismo sistêmico, confere estabilidade às expectativas dos socius.(singular)?

Dentre estas, assegura como inviolável a vida de cada um, criando obrigação de abstenção erga omnes da prática de ações que possam afetá-la.

Ocorre, todavia que, além das hipóteses abertas e toleradas pelo próprio estado como exceção, ocorrem violações à saúde e à vida para a realização de fim pretensamente lícito: pesquisas clínicas em humanos.

O perfil do sujeito "voluntário" para esses estudos revela projetos realizados de forma ilegal e eticamente censuráveis, porque não foram raras as ocasiões em que os mais vulneráveis foram utilizados como cobaias. Além dos episódios protagonizados pelos nazistas na Segunda Guerra Mundial e pelos japoneses na segunda guerra sino-japonesa, surgem outros eventos sobre a utilização de pessoas vulneráveis para fins de experiências científicas frequentemente noticiadas.

As normas aprovadas com vistas a disciplinar e orientar a matéria reconhecem a autonomia como atributo que possibilita à pessoa escolher as opções que considera melhor para si mesma. Não são ignoradas, porém as vulnerabilidades que podem ser somadas àquela original da espécie e que podem afetar decisões livres. Nesses casos, a falta de voz e de força para se contrapor acaba por constituir um estímulo para as pesquisas clínicas cujo custo constitui fato preponderante para a escolha de "voluntários". 
Entende-se, por fim, que o conteúdo de Declarações e Pactos Internacionais e exigências éticas mínimas impedem que, em nome de avanços do conhecimento em saúde, sejam desumanizadas pessoas que reclamam por acolhimento, solidariedade e apoio.

\section{REFERÊNCIAS}

Roy Mugerwa et aI., First Trial of the HIV-J Vaccine in AJi'iea: Ugandan Experience,324 BRITISH MED. J. 226, 228 (2003).

ALBUQUERQUE, Aline Para uma ética em pesquisa fundada nos Direitos Humanos. Rev. Bioética, Brasília: CFM. 2013; pp. 412-22

BEAUCHAMP, T.L. \& CHILDRESS, J.F. Princípios de Ética Biomédica. (4 ed.) São Paulo: Edições Loyola, 2002.

BUARQUE, C. Relatório sobre o caso das cobaias bumanas no Amapá. Disponivel em: <http://www.mp.ap.gov.br/noticia/leiamais.php?codnoticia=298>. Acesso em: 13 jun. 2020.

Código de Nuremberg. Disponível em https://www.ufrgs.br/bioetica/nuremcod.htm. Acesso em maio/2020

COHEN, Claudio, BUCCI Daniela A doação compulsória de órgãos e os prisioneiros condenados à morte: uma análise sob o ponto de vista da bioética. Revista de. Bioética. Brasilia: Conselho federal de Medicina, 2011; 19(2): $383-96$. 
DEAN, Gregory. General Ishii Shiro: His Legacy is that of a Genius and Madman. Electronic Theses and Dissertations. Paper 1010. Disponível em: https://dc.etsu.edu/etd/1010. 2005.

Diniz, Débora. Dirceu Guilhem. O que é bioética. São Paulo: Brasiliense, 2007.

Disponível em: https//ahrp.org.1944-1956-radioative-nutrictions experiments. Acesso em 21 maio 2019.

Disponível em: https: Ética em conflito.wordpress.com/pesquisas-comhepatite-na-escola-estadual-de-willowbrook. Acesso em 21 maio 2019.

Disponível

em: https://moodle.ufsc.br/pluginfile.php/1329334/mod resource/content/ 1 /informe belmont.pdf Acesso em: maio/2020. ?????

FAIVRE, Anne-Sophie Le Cader, Le coronavirus, les tests de vaccins et l'Afrique: où en est-on? Disponível em: https://factuel.afp.com/lecoronavirus-les-tests-de-vaccins-et-lafrique-ou-en-est

FERRER, Jorge José. ALVAREZ, Juan Carlos. Para fundamentar bioética: teorias e paradigmas teóricos na bioética contemporânea.

GRECO, Dirceu. WELSH, James. Direitos humanos, ética e prática médica. Revista Bioética. Vol. 24(3), 2016 - p. 443-451. p, 446. Disponível em: $\quad$ https://www.scielo.br/pdf/bioet/v24n3/1983-8042-bioet-24-030443.pdf

GRECO, Dirceu. WELSH, James. Direitos humanos, ética e prática médica. Revista Bioética. Vol. 24(3), 2016 - p. 443-451. p, 446. Disponível 
em: https://www.scielo.br/pdf/bioet/v24n3/1983-8042-bioet-24-030443.pdf

GRECO, Dirceu. WELSH, James. Direitos humanos, ética e prática médica. Revista Bioética. Vol. 24(3), 2016 - p. 443-451. p, 448. Disponível em: https://www.scielo.br/pdf/bioet/v24n3/1983-8042-bioet-24-030443.pdf

https://www.epochtimes.com.br/partido-profissao-abuso-transplanteorgaos-china/ Aceso em: 5.jul. 2020.China legitima seu sistema de transplantes, mesmo sem transparência ... -Em https://noticias.uol.com.br/ultimas-noticias/afp/2018/07/06/chinalegitima-seu-sistema-de-transplantes-mesmo-semtransparencia.htm?cmpid=copiaecola Acesso em: 4 de jul. 2020.

KANT, Emanuel. Fundamentação da metafísica dos costumes. Lisboa: Edições 70, 2007.

Kotow, Miguel. Participación informada em clínica e investigación biomédica: las multiples facetas de la decisión e el consentimento informados. Red Latinoamericana y del Caribe de Bioética: Universidad Nacional de Colombia, 2007.

LINS, Emmanuela Vilar. As dimensões da vulnerabilidade humana: como condição, como característica e como princípio bioético-jurídico. Salvador: Universidade Federal da Bahia, 2007.

MESTIERI, João. Curso de direito criminal. São Paulo: Alba, 1979, p.30. 
NYISZLI, Miklos. Auschiwtiz: o testemunho de um médico. Tradução: Roberto Golddkorn. Editora: Distribuidora Record, Rio de Janeiro/São Paulo: 1974.

ROCHA, Alexandre. Autonomia: a invenção do indivíduo. Potumac, Washigton Dc, p 26. 2020, no prelo.

TORRALBA, Roselló Francese. Ideias de dignidade. Uma exploracion filosófica. Em: MARTINEZ, Julio Perrotin Catherine, TORRABA, Francese. Repensar la dingidad humana. San Salvador: Milenio, 2005, p. 1592.

ROTHMAN, David J. Were Tuskegee and Willoubrook Studies in Nature? The Hasting Centrer Report vol 12, n ${ }^{\circ}$ 2, abr. 1982, pp.5-7. p.5. Disponível em: http//jstor.org/stable/3561798. Acesso em: 21 maio 2019.

ROTHMAN, David J. Strangers at the Bedside: a History of how Law and Bioethics Transformed Medical Decision Making. USA. Basic Books, 1991. WHITE, Becky Cox. Competence to consent. Washington: Georgetown University Press, 1994. 